\title{
Influence of current type on tribological and corrosion properties of nickel boron coatings produced by electrodeposition
}

\author{
U. Barut*, R. Karslioğlu \\ Department of Metallurgical and Materials Engineering, Yıldırım Beyazıt University, Ankara, 06010, Turkey
}

Received 12 July 2018, received in revised form 14 February 2019, accepted 26 February 2019

\begin{abstract}
In the present work, Ni-B alloys were successfully coated on the low carbon steel substrate from a modified watt type bath with direct current, pulse current and pulse reverse current. Effects of current type on microstructure and surface morphology were characterized via scanning electron microscopy. Crystallographic orientation, lattice distortion and grain size changing with different current type were investigated with X-ray diffraction. High lattice distortion and lower grain size performed with pulse current and pulse reverse current type respectively. Mechanical studies imply that pulse current type provides the highest microhardness values. Tribological properties of alloys carried out reciprocating sliding wear tests. Reciprocating sliding wear tests evidenced that the alloy coatings deposited by using pulse current and pulse reverse current demonstrated substantial advancement in mechanical properties and wear resistance because of the current type. Pulse current and pulse reverse current provide higher wear resistance when compared with plating produced via direct current. According to the corrosion test results, the highest corrosion resistance was obtained by direct current, and the lowest corrosion resistance was obtained by pulse reverse current. The result is that the grain size is the main factor for corrosion resistance.
\end{abstract}

K e y w o r d s: electrodeposition, current type, nickel boron, wear, corrosion

\section{Introduction}

The surface coating technology has largely been carried out for the last few years in several engineering fields such as automobiles, electronics, aviation, daily necessities, etc. In these areas, hard chrome plating is widely used. Hard chrome platings have various advantages, such as great corrosion resistance, high stiffness and surface smoothness, but they are dangerous against the environment and human body because of containing hexavalent chromium $\left(\mathrm{Cr}^{+6}\right)[1-3]$. Therefore, alternative coatings for hexavalent chrome coatings should be available.

Nickel $(\mathrm{Ni})$ coatings provide a proper alternative and have been largely used in engineering applications for the last five decades due to their unique properties that enhance wear, abrasion and corrosion resistance [4]. However, when compared to hard chrome plating, nickel coatings are inferior in durability and hardness. Therefore, such as Ni-Mo, Ni-Fe, Ni-W, Ni-P, Ni-Co and Ni-B, Ni-based alloy coatings have been improved to obtain better mechanical characteristics [5-10].

$\mathrm{Ni}-\mathrm{B}$ alloy coatings have outstanding properties when compared to other Ni alloy coatings. Ni-B coatings have been used in various industrial applications $[11,12]$, because of good corrosion resistance, long durability, high hardness and proper solderability. Electrodeposition and electroless coating processes are often used for producing $\mathrm{Ni}$ alloys coatings [4]. Electroless nickel coating is occurred by the reduction of nickel ions by the boron hydride and also boron hydride coating bath is carried out at high $\mathrm{pH}$ conditions, at $80-90^{\circ} \mathrm{C}$. In these circumstances, metallic nickel which is not tightly connected to the film can precipitate owing to spontaneous decomposition of the reducing agent (boron hydride). Stabilizers (such as sulfur heterocyclic compounds or heavy metal ions) are added into the bath to prevent spontaneous precipitation [13].

Electrodeposited Ni-B alloy coatings typically come true at lower temperatures, around $50^{\circ} \mathrm{C}$, and are conventionally used with boron hydrides, boric

*Corresponding author: e-mail address: ubarut@ybu.edu.tr 
Table 1. Bath composition and electrodeposition conditions of the coating bath

\begin{tabular}{llll}
\hline \multicolumn{2}{c}{ Bath composition } & \multicolumn{1}{c}{ Electrodeposition conditions } \\
\hline $\mathrm{Ni}\left(\mathrm{SO}_{4}\right) \cdot 6 \mathrm{H}_{2} \mathrm{O}$ & $250 \mathrm{~g} \mathrm{l}^{-1}$ & Temperature & $55^{\circ} \mathrm{C}$ \\
$\mathrm{H}_{3} \mathrm{BO}_{3}$ & $40 \mathrm{~g} \mathrm{l}^{-1}$ & $\mathrm{pH}$ & $4-5$ \\
$\mathrm{TMAB}$ & $2.5 \mathrm{~g} \mathrm{l}^{-1}$ & Stirring speed & $250 \mathrm{rpm}$ \\
& & Time & $30 \mathrm{~min}$ \\
& & Current type & $\mathrm{DC}, \mathrm{PC}, \mathrm{PRC}$ \\
& & Current density & $5 \mathrm{Adm}^{-2}$ \\
\hline
\end{tabular}

acid $[14,15]$. The absence of strong reducing agents in electroplating prevents the self-catalytic precipitation of Ni particles from solution [16] and makes this process inherently more stable than electroless deposition.

The Ni-B alloy coatings are generally prepared by the electrodeposition method from $\mathrm{Ni}$ bath solution which contains triethylamine borane (TMAB) $[14,17]$, dimethylamine borane (DMAB) as a boron source $[18$ $20]$. In recent years, the use of DMAB or TMAB has been proposed in some publications $[17,18]$.

Electroplating is well-known as a typical plating method of alloy thin films on metal. For this method, it is easy to check the growth rate, and also it is low cost and simple method [21,22]. Direct Current (DC) is most widely used for electroplating. Pulse Current (PC) and Pulse Reverse Current (PRC) are alternative methods for DC to prepare metallic films [23]. For alloy films, the application of PC enables the incorporation of particles in high concentration in addition to a wider range of deposit compositions.

Furthermore, it is also possible to control the deposited film composition and thickness at the atomic level by regulating the pulse amplitude and width [24, 25]. In the $\mathrm{PRC}$ technique [23, 26] a stripping time is introduced into the plating cycle, during which the metal surface protrusions selectively dissolve, which provides a uniform deposit. This feature makes this technique most adequate for the preparation of alloys $[26,27]$.

The main objective of this study is to produce coatings with mechanical properties such as high hardness, good wear resistance which have increased in importance in recent years. Although there are literature reports on the production of such coatings under DC, PC and PRC currents, there is no study to optimize tribological properties and corrosion properties by using three different methods. It is aimed to contribute to the universal literature from this point of view.

\section{Experimental}

\subsection{Electrodeposition}

In this study, Ni and Ni-B alloy were coated with a different type of electrodeposition method. Low car- bon steel $\left(40 \times 20 \times 1.5 \mathrm{~mm}^{3}\right)$ was used as the substrate. The substrate was cleaned mechanically and chemically. Firstly, the surface of the substrate was ground with $\mathrm{SiC}$ grind papers (400 and 600 mesh) to clean it from dust and decrease surface size roughness. Subsequently, the surface was cleaned with pure water, acetone and ethanol before coating. Ni metal plate $\left(50 \times 25 \times 3 \mathrm{~mm}^{3}\right)$ was used as an anode material. High-purity nickel sulfate $\left(\mathrm{NiSO}_{4} \cdot 6 \mathrm{H}_{2} \mathrm{O}\right)$, provided by Merck Co., was used as Ni source. Trimethylamine boron (TMAB) which is provided by SigmaAldric Co. was used as the boron ion source. Boric acid $\left(\mathrm{H}_{3} \mathrm{BO}_{3}\right)$ was used to stabilize the $\mathrm{pH}$ value of the coating bath. The plating bath composition and electrodeposition conditions used in the electroplating operation are presented in Table 1.

Ni-B alloy coatings were produced with different current types (DC, PC, PRC) and under constant average current density $\left(5 \mathrm{~A} \mathrm{dm}^{-2}\right)$ for $30 \mathrm{~min}$. After coating, Ni-B alloy coatings were cleaned with pure water and dried in air at room temperature.

\subsection{Structural characterization}

The structural and phase analyses of the electrodeposited Ni-B were determined using an X-ray diffractometer (Rigaku-Miniflex 600) with a $\mathrm{CuK} \alpha$ radiation $40 \mathrm{kV}$ and $15 \mathrm{~mA}$. The $\mathrm{Cu} \mathrm{K} \alpha$ wavelength of radiation is $1.546 \AA$. The diffraction patterns were gathered in step scan mode and recorded in $2^{\circ}(2 \theta)$ steps at 1 minute per step between $20^{\circ}<2 \theta<110^{\circ}$. The full widths at half maximum (FWHM) values of X-ray diffractions were utilized to calculate grain sizes by using the Debye-Scherrer formula in Eq. [28]:

$$
D=\frac{K \lambda}{\beta \cos \theta},
$$

where $K$ is a Scherrer constant ( $K \sim 0.9$ in this case), $\lambda$ is the wavelength of X-ray ( $\lambda \mathrm{CuK} \alpha 1 \sim 1.546 \AA), \theta$ is the diffraction angle, and $\beta$ is full width at half maximum (FWHM).

The surface morphologies of electrodeposited Ni-B films were studied by Scanning Electron Microscope (SEM, Hitachi-TM4000 Plus). The thicknesses of the Ni-B films were measured at ten randomly selected locations of each specimen from the cross-section of SEM images. The thickness values were averaged. 

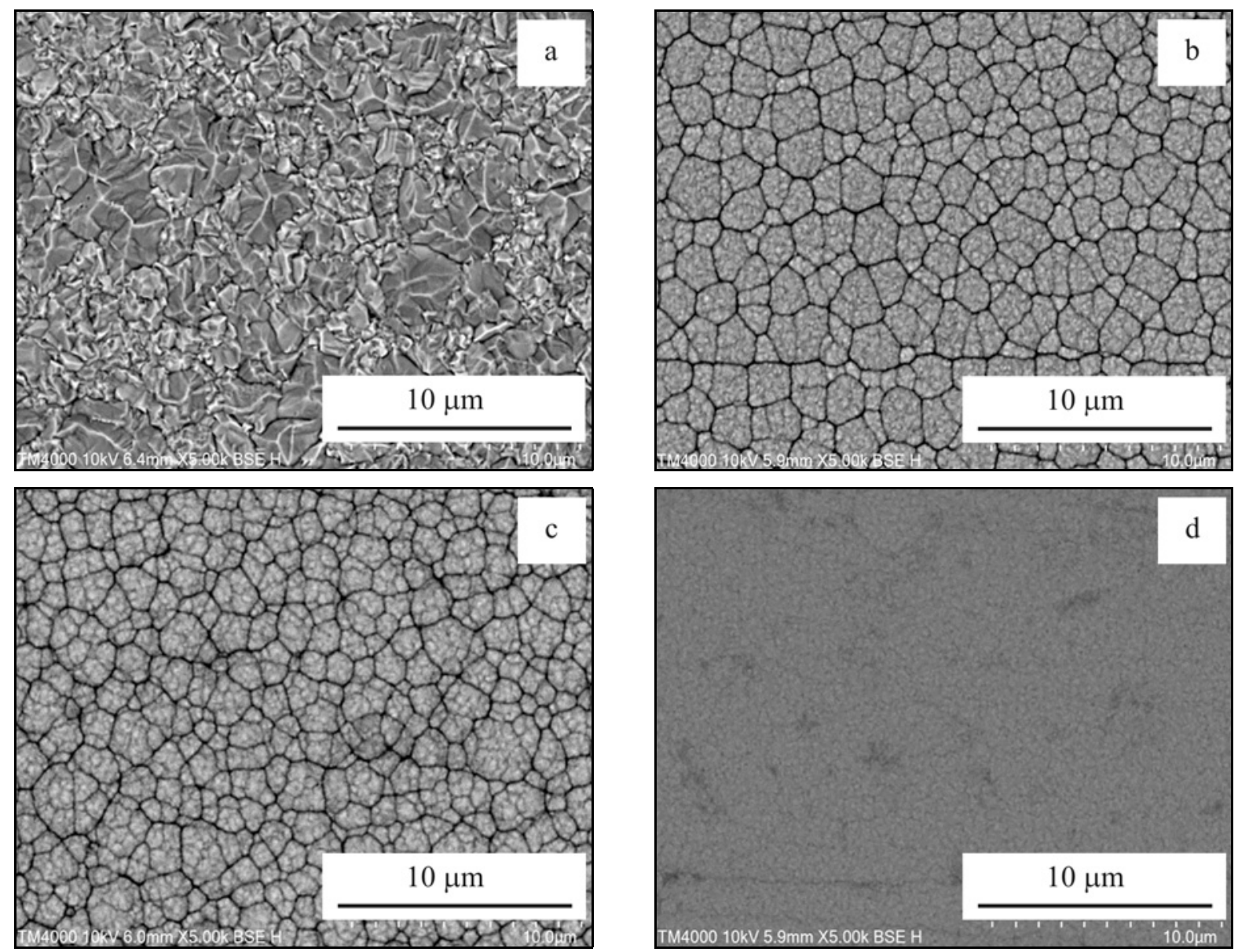

Fig. 1. SEM images of pure nickel coating and Ni-B alloy coatings at $5 \mathrm{~A} \mathrm{dm}^{-2}$ current density, at $55^{\circ} \mathrm{C}$, within $30 \mathrm{~min}$ : (a) pure nickel (DC), (b) DC, (c) PC, and (d) PRC methods.

\subsection{Hardness, wear and corrosion tests}

The microhardness of the Ni-B films was calculated by using Vickers microhardness test device (Shimadzu-HMV-G 21S) carrying out a load of $50 \mathrm{~g}$ for $10 \mathrm{~s}$. At least, ten measurements were applied, and average values were taken as references. The wear resistance of Ni-B alloy coatings was evaluated by using high-frequency reciprocating wear test machine. The reciprocating wear behavior of the coatings sliding against an $\mathrm{Al}_{2} \mathrm{O}_{3}$ ball $(\varnothing 10 \mathrm{~mm})$ was investigated on a tribometer according to DIN 50324 and ASTM G 99-95a in a ball-on-disk configuration. The wear tests were operated at ambient temperature and under non-lubricated conditions in the air with relative humidity of $35 \pm 5 \%$. The wear tests were carried out at sliding speeds of $75 \mathrm{~mm} \mathrm{~s}^{-1}$ with a fixed applied load of $1.0 \mathrm{~N}$. For each specimen, the chosen total sliding distance was $250 \mathrm{~m}$, the reciprocating sliding motion was adjusted as $12 \mathrm{~mm}$ with a $+6 \mathrm{~mm}$ and $-6 \mathrm{~mm}$. After wear tests finished, the average friction and wear results were taken from software. A complete microstructural characterization of worn surfaces was performed by SEM (Hitachi-TM4000 Plus).
The corrosion resistance of pure nickel coating and $\mathrm{Ni}-\mathrm{B}$ alloy coatings were measured with potentiodynamic polarization test device (CH Instruments) at room temperature in $3 \mathrm{wt} . \% \mathrm{NaCl}$ aqueous solution via a three-electrode cell system, in which $\mathrm{Ni}-\mathrm{B}$ alloy coatings were set as the working electrode, $\mathrm{Ag} / \mathrm{AgCl}$, graphite rod electrodes were used as the reference and counter electrodes.

\section{Results and discussion}

Figure 1 shows SEM surface images of electrodeposited pure nickel and Ni-B alloy coatings. Typical surface morphologies of pure nickel and Ni-B films produced by DC, PC and PRC methods on the low carbon steel substrates are shown in Figs. 1a-d, respectively. Figure 1a shows that the microstructure with the largest grain belongs to pure nickel. Figure 1b shows the morphology of a DC, which had a relatively large grain size and showed different sized crystals. Carrying out the PC method (Fig. 1c), leads to a decrease in the grain size of the Ni-B alloy. Figure 1d reveals that the Ni-B alloy coatings, electrodeposited by PRC 

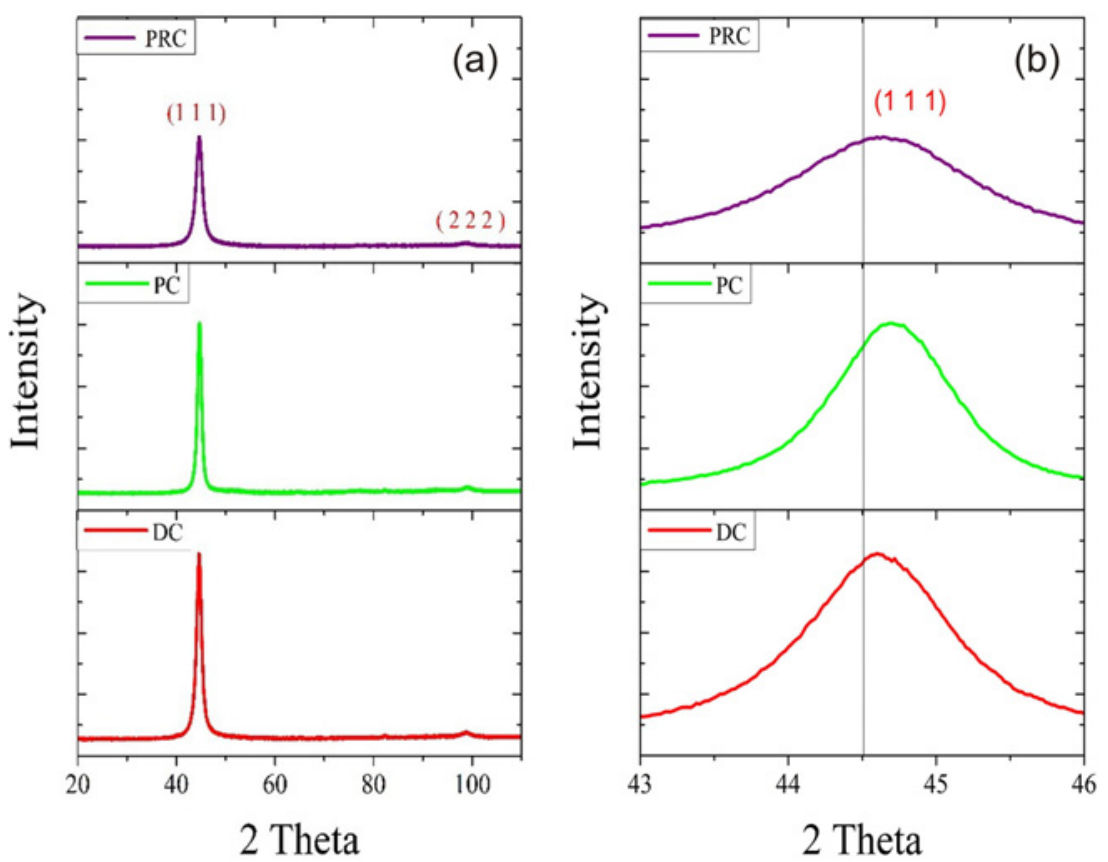

Fig. 2. (a) Influence of current types on phase structure in electrodeposited Ni-B coatings prepared by DC, PC, PRC, (b) detailed analysis of XRD patterns of the Ni-B alloy coatings deposited at different current types.

method, have surface accumulated with a high number of equally sized very fine grains.

The structural analysis of the Ni-B alloy coatings was carried out by X-ray diffraction (XRD) in this study. The XRD patterns for electrodeposited Ni-B films produced via DC, PC, PRC methods are shown in Fig. 2a. It can be demonstrated that the microstructure of Ni-B alloy coatings is based on the current type. Two diffraction peaks located at about $44^{\circ}$ and $98^{\circ}$ were determined for $\mathrm{Ni}-\mathrm{B}$ alloy coatings which were detected the $\left(\begin{array}{lll}1 & 1 & 1\end{array}\right)$ and $\left(\begin{array}{lll}2 & 2 & 2\end{array}\right)$ reflection planes of nickel. For Ni-B alloy coatings, the highest intensity of peak was detected $\left(\begin{array}{lll}1 & 1 & 1\end{array}\right)$ plane. Also, we could detect some (2 22 2) growing planes. The highest and the sharpest peak were obtained by the DC method. When current type was converted from DC to PC, there was observed a decrease in the $\left(\begin{array}{lll}1 & 1 & 1\end{array}\right)$ plane which is the dominant growth direction. By PRC method, the lowest peak density and the largest peak range were obtained. This is the indication of the largest grain size in the DC type. Also, the smallest grain size was obtained by PRC method. The similar results were reported in Ni-Co alloy coatings by Karslioglu et al. [29]. Also, there is no peak associated with $\mathrm{B}$ or Ni-B; it refers that boron atoms were finely deposited in the crystalline lattice of Ni. Similar results were presented by Chang et al. [30], Ogihara et al. [21] and Lopez [25].

The crystallite size of the electrodeposited Ni-B films was measured from the width of the $\mathrm{Ni}\left(\begin{array}{lll}1 & 1 & 1\end{array}\right)$ peak observed in the X-ray diffractograms using Debye-Scherrer method. According to results obtained from the Debye-Scherrer method, the crystallite size of Ni decreases from DC to PRC in the Ni-B coatings. Grain sizes of the alloy coatings produced by DC, PC and PRC are 9.39, 7.48 and $5.94 \mathrm{~nm}$, respectively. The highest grain size of Ni-B alloy coatings was achieved with DC type. The Ni-B coating prepared via PRC revealed the finest grain size at almost $5.94 \mathrm{~nm}$. The relationship between grain size and current type in Ni-B alloy coatings is shown in Fig. 9.

Detailed analysis of XRD patterns of the Ni-B alloy coatings deposited at different current types is shown in Fig. 2b. According to JPDS card no: 00-004-0850 for pure nickel, the highest peak value is $44.51^{\circ}$, and this value is indicated by ascending in Fig. 1b. In the coating prepared by DC, the value of $(2 \theta)$ angle shifted from $44.51^{\circ}$ to $44.597^{\circ}$ which resulted in distortion during electroplating. In the PC type, the $2 \theta$ angle corresponding to the $\left(\begin{array}{lll}1 & 1 & 1\end{array}\right)$ plane shifted from $44.51^{\circ}$ to $44.671^{\circ}$. However, for the PRC type, the $2 \theta$ angle corresponding to the $\left(\begin{array}{lll}1 & 1 & 1\end{array}\right)$ direction is closer than the value $\mathrm{PC}$ in the original JPDS card, as a result of re-decomposing the high energetic directions with the applied current. This shows that internal stress and lattice distortion for PRC method are less than those for the PC method.

Figure 3 shows the microhardness of pure nickel coating produced by DC and the influence of current types on microhardness of the Ni-B alloy coatings produced by direct, pulse and pulse reverse currents. The microhardness of the pure nickel prepared by DC was calculated. The microhardness of all Ni-B films is higher than that of pure nickel produced by 


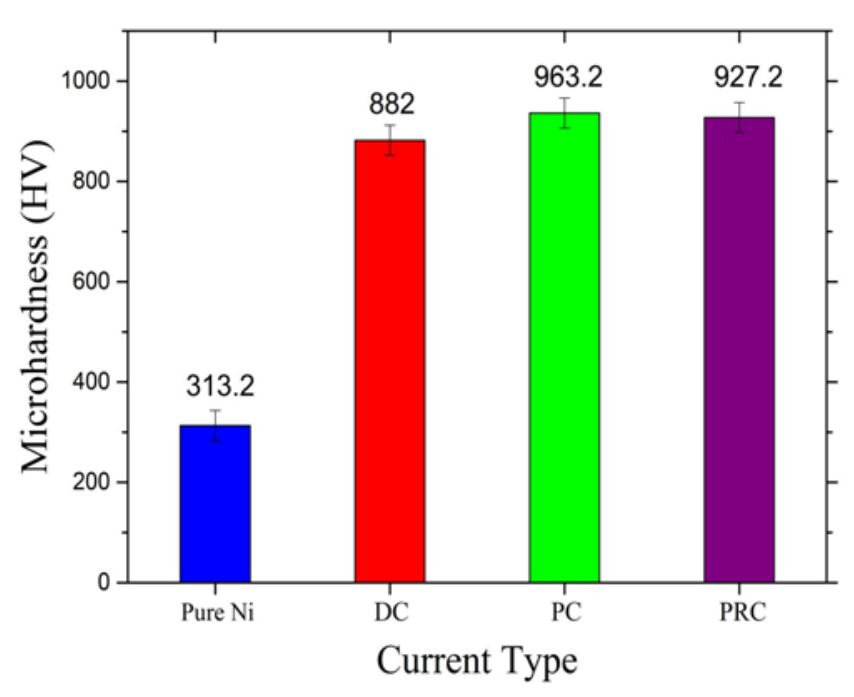

Fig. 3. Values of microhardness versus current type for pure nickel coating and Ni-B alloy coatings.

DC. The highest microhardness was achieved by PC in Ni-B alloy coatings, and the lowest microhardness was obtained in pure Ni. It can be concluded that the hardness of the alloy coatings rises with the addition of TMAB. Microhardness of the coatings generally increases with this array of electrodeposition conditions: DC, PRC and PC. Important improvement has been attained in the hardness of Ni-B alloy coatings with PC and PRC deposition methods. The microhardness of DC in Ni-B alloy coating showed $882 \mathrm{HV}$ and increased to $927.2 \mathrm{HV}$ with PRC method and to 963.2 with PC method. Since the crystallographic grain growth orientation and the thinner grain size changed, such a result came about [29]. The increase of microhardness by the PC and PRC is significantly high.

Figure 4 proves that the microhardness of coating has an important influence on the wear resistance and coefficient of friction. Figure 4 demonstrates the relationship between the friction coefficient and current type for pure nickel prepared by DC and other alloy coatings. The pure nickel produced by DC has the lowest hardness, and the hardness of coating produced by PC in Ni-B alloys is the highest. It can be observed from these values that the friction coefficient of pure nickel is less when compared to results attained for $\mathrm{Ni}-\mathrm{B}$ electroplatings. Because pure Ni has an enormously low hardness (313.2), a critical plastic deformation takes place throughout the tribological test for pure nickel coating [30]. Consequently, the coefficient of friction for pure nickel is lower than for other coatings.

The wear volume values of all coatings are shown in Fig. 5. As seen from Figs. 3 and 5, with increasing microhardness of the coatings, the wear volume decreases in this sequence as follows: pure nickel

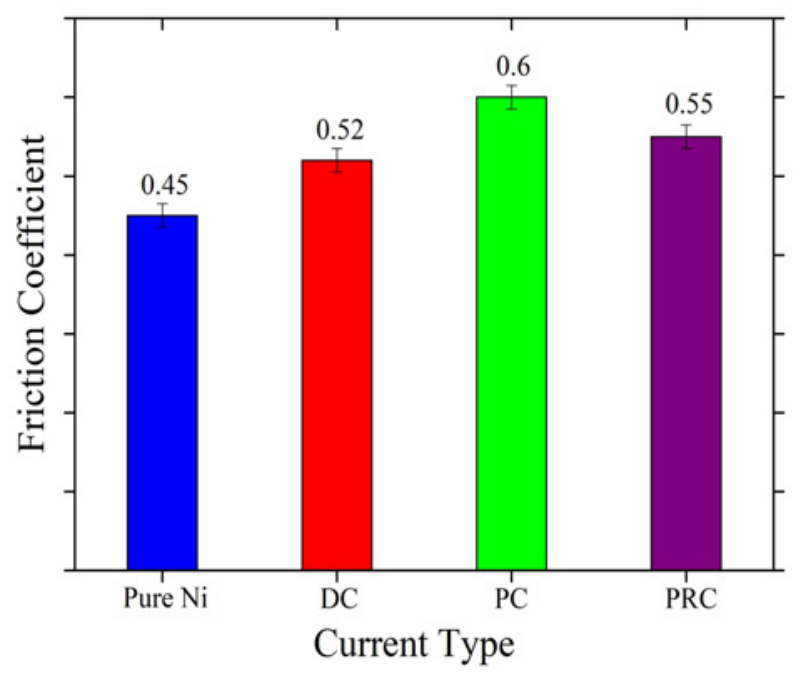

Fig. 4. The relationship between friction coefficient and current type in pure nickel coating prepared by DC and Ni-B alloy coatings.

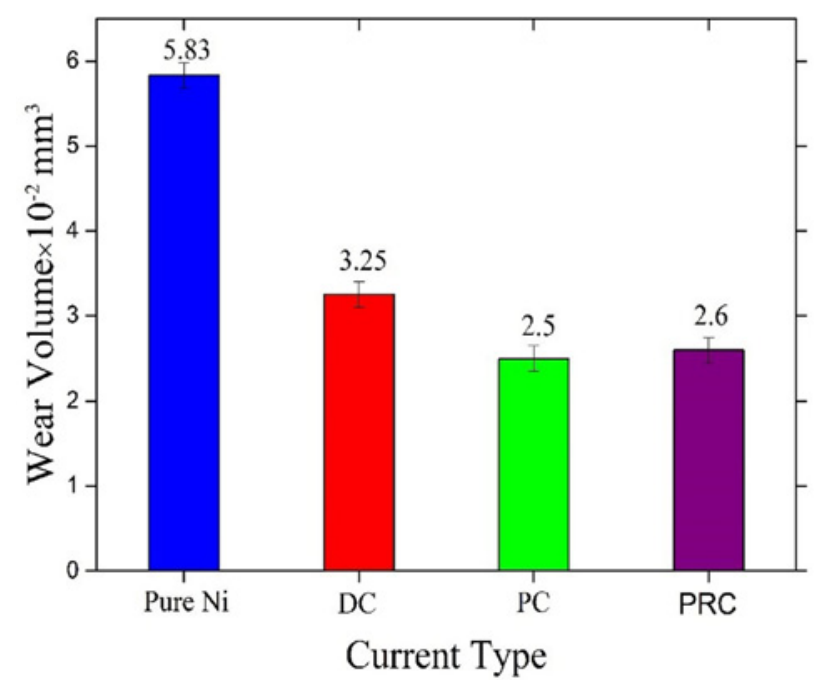

Fig. 5. Values of wear volume versus current type for pure nickel coating and Ni-B films.

$\left(5.83 \times 10^{-2} \mathrm{~mm}^{3}\right), \mathrm{DC}\left(3.25 \times 10^{-2} \mathrm{~mm}^{3}\right), \mathrm{PRC}$ $\left(2.6 \times 10^{-2} \mathrm{~mm}^{3}\right), \mathrm{PC}\left(2.5 \times 10^{-2} \mathrm{~mm}^{3}\right)$. Chang et al. [30] studied the influence of different density for DC on different amounts of boron in Ni-B films prepared from bath including TMAB and informed that the wear volume significantly decreased and microhardness of coating, which is compatible with our present results, increased. The wear volume of pure nickel is about 2.3 times more than that of PC coating. These results are following Archard's equation that the wear of a material is inversely proportional to its hardness. Therefore, it can be deduced that arranging the electroplating current type lets for accurate control of 


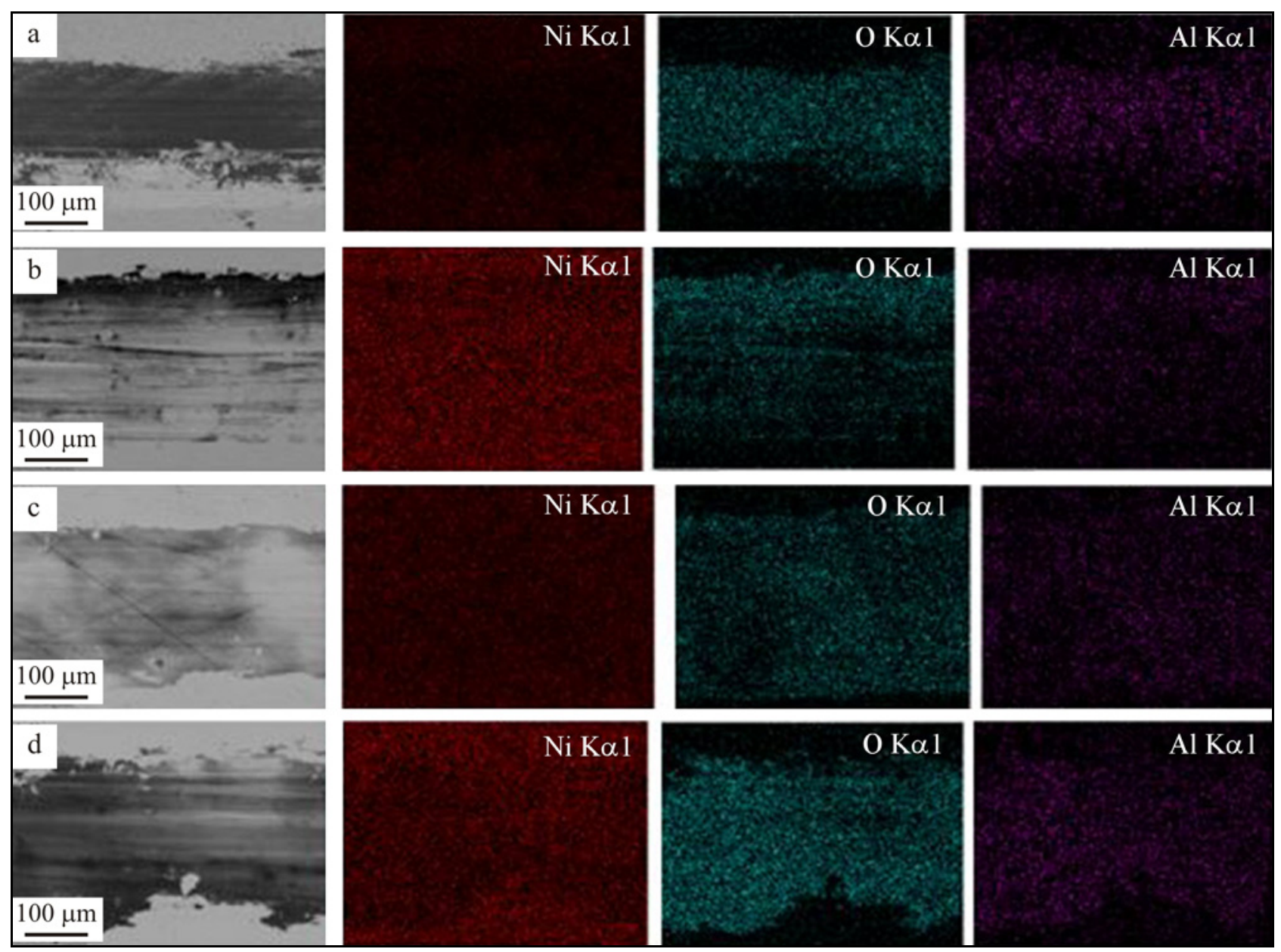

Fig. 6. EDS dot-map analysis of coatings prepared by (a) pure nickel coating prepared by DC, and Ni-B alloy coatings prepared by (b) DC, (c) PC, and (d) PRC.

microhardness. Hansal et al. [31] investigated pulsedelectrodeposited NiP-SiC coatings, and their research also showed an increase in wear volume of coatings produced by the PC.

SEM images of worn surfaces and EDS dot-map analysis of pure nickel and the Ni-B alloy coatings prepared by different current types and tested at the slip velocity of $75 \mathrm{~mm} \mathrm{~s}^{-1}$ are shown in Fig. 6. The surface of the pure nickel coating was more worn than that of the other alloy coatings. The entire surface of the worn area of pure nickel coating is damaged, while the surface of the Ni-B alloy coatings shows damage as partly deformed contact points. This means that worn tracks of pure Ni coating showed extensive delamination cracks due to low hardness of pure Ni compared to the alloy coatings. The dot-map analysis taken from the DC coating after wear testing shows oxidation is lower than that for PC and PRC coatings. When the coefficient of friction decreases, the heat generated between the substrate material and the alumina ball during friction is less. Therefore, less oxidation occurs. One important reason is that there are less alumina and oxygen transfer from the counter material due to the low hardness of the coating. Therefore, the total amount of oxygen in the map analysis obtained from the wear trace is less.

Figure 7 shows SEM images of worn surfaces after wear testing of the Ni-B films tested at the slip velocity of $75 \mathrm{~mm} \mathrm{~s}^{-1}$ : (a) pure nickel (DC), (b) DC, (c) PC, (d) PRC platings. A thin oxidized layer on the surfaces of Ni-B films was tested at a slip velocity of $75 \mathrm{~mm} \mathrm{~s}^{-1}$. The wear products which are thought $\mathrm{Ni}$ and $\mathrm{B}$ essentially were oxidized on the Ni-B film surfaces with sliding against $\mathrm{Al}_{2} \mathrm{O}_{3}$ ball. As reported earlier by Karslioglu et al. [29], the formation of metal oxides and an increase in the contact temperature has been a result of repeated reciprocating sliding. Owing to fatigue mechanisms, micro-cracks occur in these metal oxides. As a result, the stress accumulation around the sample and the ball ends up with delamination types of wear products.

The wear mechanism of pure Ni produced by DC resulted in intensive delamination and fragmentation from the surface. It is observed that the abrasive wear mechanism is dominantly showed in the DC coating. PC coating demonstrated abrasive and adhesive wear. 

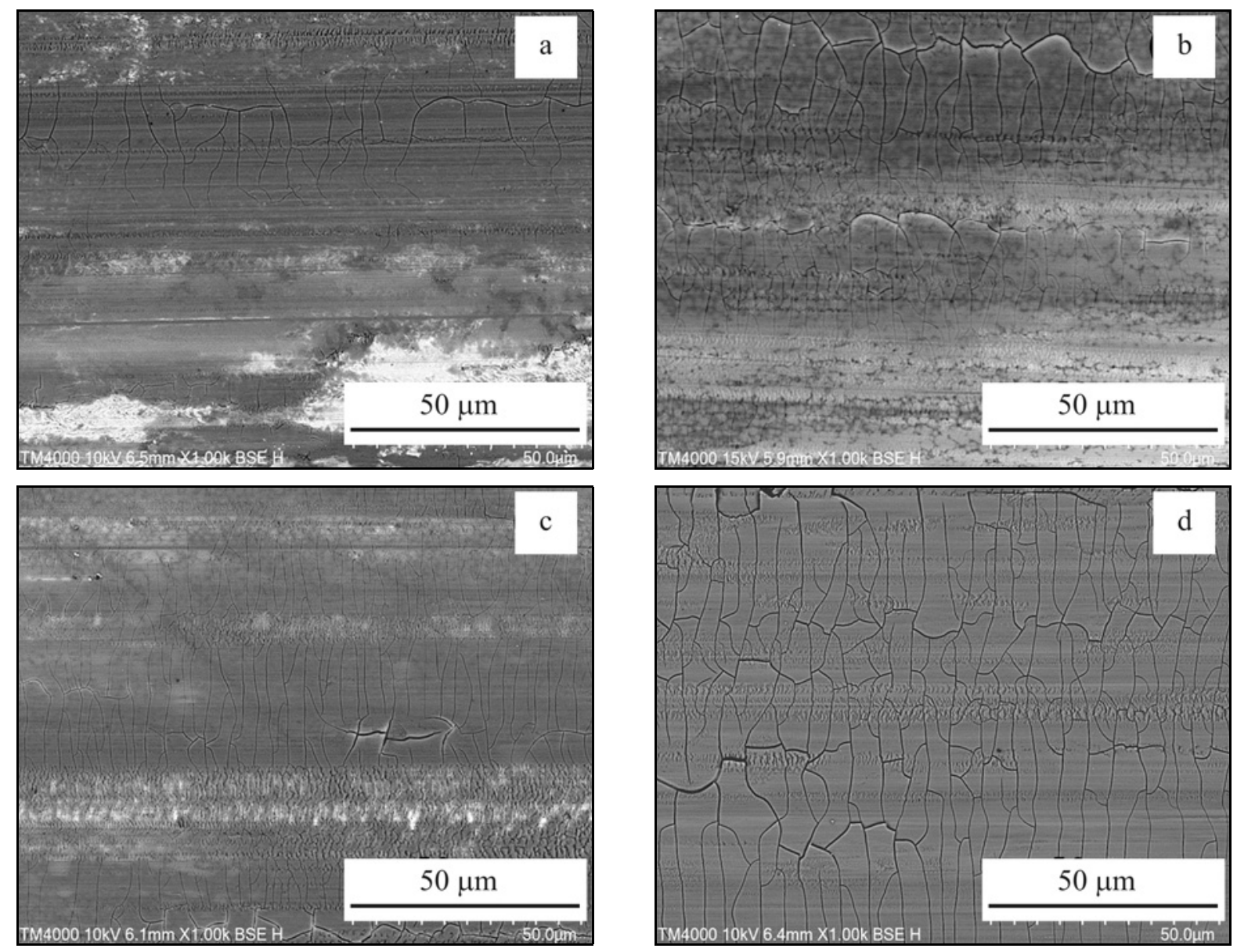

Fig. 7. SEM images of the worn surface of (a) pure nickel coating and Ni-B alloy coatings produced by (b) DC, (c) PC, and (d) PRC types at the slip velocity of $75 \mathrm{~mm} \mathrm{~s}^{-1}$.

When compared to pure nickel (DC) and Ni-B coating prepared by DC, excessive deformation in the pure nickel coating was observed, and this deformation was observed as only abrasive traces in the $\mathrm{Ni}-\mathrm{B}$ coating produced by DC. By comparison with DC coating, abrasive traces observed in the structure decreased in PC coating, and the cracked structures caused by delamination cracks in the DC coating were shrunk in the PC coating due to load and high contact temperature. Furthermore, cracked structures caused by delamination grew again in the PRC coating, there was an increase in delamination cracks due to the finer grain size of the structure in the PRC coating, and therefore the wear resistance was lower than in the PC coating.

The polarization curves for pure nickel and electrodeposited Ni-B films are shown in Fig. 8. At the beginning of the corrosion test, in contrast to pure nickel coating, in the polarization curves of electrodeposited Ni-B films, passive film formation was observed on the surface of samples. Furthermore, the corrosion current density $\left(I_{\text {corr }}\right)$ of Ni-B coating obtained by PRC method was the highest among all alloy coatings.

In Fig. 9, it is clearly shown that the corrosion

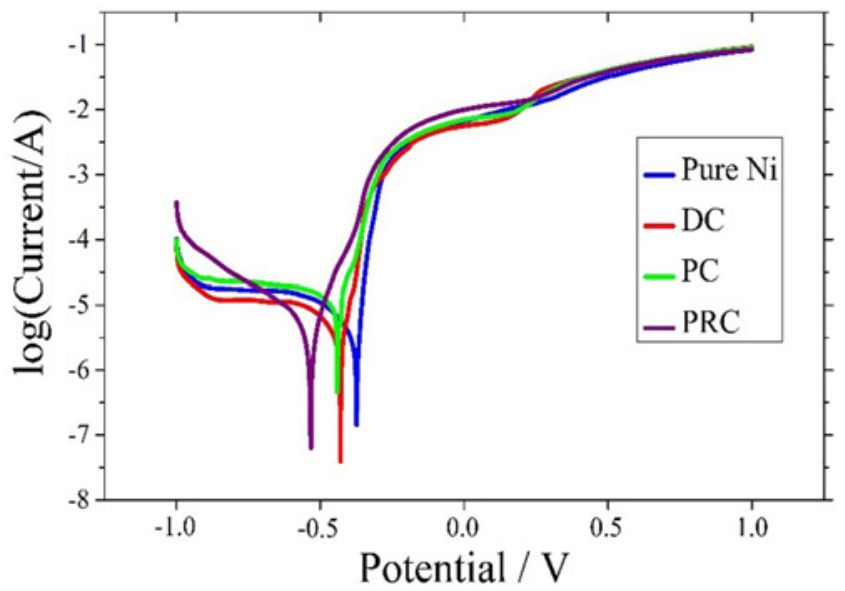

Fig. 8. Polarization curves of pure nickel coating and Ni-B films produced with a scan speed of $0.5 \mathrm{mV} \mathrm{s}^{-1}$ in $3 \mathrm{wt} . \%$ $\mathrm{NaCl}$ solution.

current of Ni-B alloy coatings decreased with an increase in grain size. Regarding the current type effect on the corrosion resistance of $\mathrm{Ni}-\mathrm{B}$ alloy coatings, it demonstrates that the corrosion current density in- 


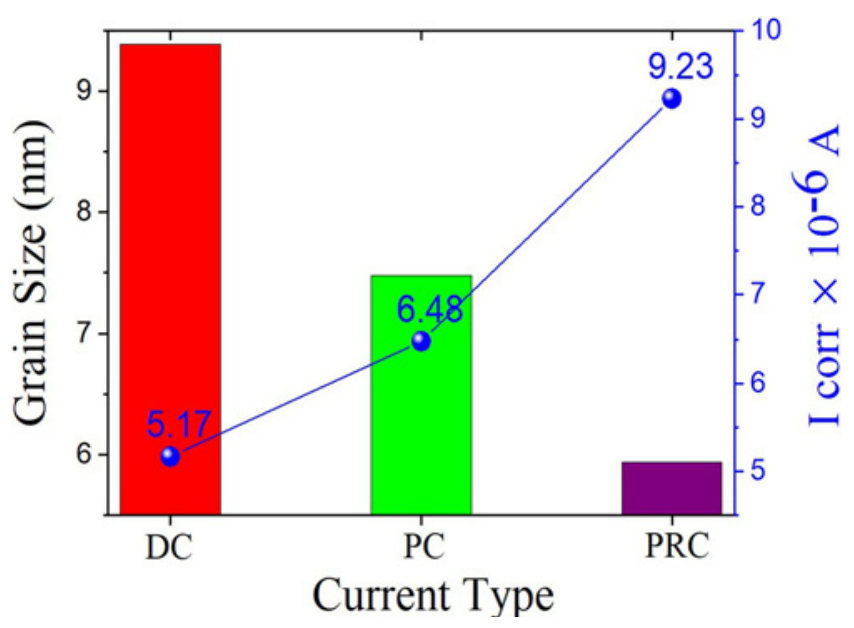

Fig. 9. Corrosion potential and grain size of Ni-B alloy coatings prepared by different current types.

creases from DC to PRC. Furthermore, as the corrosion current decreases, the resistance of corrosion increases.

The rise of the resistance to corrosion with rising grain size can be clarified by the fact that there are more grain boundaries in small grains when compared to large grains. The grain boundaries are more easily affected by corrosion because of their low stability and high energies. Also, the corrosion solution can penetrate Ni-B coatings through grain boundaries and reach the substrate, ending up with diminishing resistance of corrosion. For this reason, the reduction of grain size reduces the corrosion resistance. According to the results obtained from XRD, the highest grain size was obtained by the DC method, and the lowest grain size was obtained by the PRC method. According to these data, the XRD and the corrosion test results are consistent.

The results found by Chang et al. are similar [30]. They studied electrodeposited Ni-B alloy coatings with different amounts of the boron prepared via direct current in a bath including trimethylamine borane at $0.06 \mathrm{M}$. Their results show that as the grain size increases, the resistance of corrosion rises.

\section{Conclusions}

In this study, the influence of mechanical properties, corrosion and wear resistance on electrodeposited $\mathrm{Ni}-\mathrm{B}$ coatings obtained by different current types were investigated. The obtained results are as follows:

1. Hardness and microstructure of the Ni-B alloy coatings were considerably influenced by the different current type and TMAB addition. The hardness of pure nickel produced by DC, which is $313.2 \mathrm{HV}$, reached up to $882 \mathrm{HV}$ with the addition of TMAB and this value increased to $963.2 \mathrm{HV}$ for different current types. Also, the lowest grain size was obtained by PRC method.

2. All the Ni-B alloy coatings prepared by DC, PC, PRC methods exhibited predominant growth in the (1 11 1) planes. The grain size was attained between 5.94 and $9.39 \mathrm{~nm}$. According to the JPDS card of pure nickel, it was observed that the lowest distortion occurred in the DC coating in the detailed XRD results of the coatings. In the $\mathrm{PC}$ type, the $2 \theta$ angle corresponding to the $\left(\begin{array}{lll}1 & 1 & 1\end{array}\right)$ plane shifted from $44.51^{\circ}$ to $44.671^{\circ}$. However, in the PRC type, the $2 \theta$ angle corresponding to the $\left(\begin{array}{lll}1 & 1 & 1\end{array}\right)$ direction is closer than the value $\mathrm{PC}$ in the original JPDS card, as a result of re-decomposing the high energetic directions with the applied current. This shows that internal stresses and lattice distortion are less than those for PC.

3. Ni-B alloy coatings produced by three different current types demonstrated better wear resistance as compared to pure $\mathrm{Ni}$ coating. TMAB addition increased friction coefficient and wear resistance. Also, the highest wear resistance was achieved by PC type. It was observed that the abrasive wear mechanism was dominantly showed in the DC coating. PC coating demonstrated abrasive and adhesive wear. With PRC type, there is an increase in delamination cracks due to the finer grain size of the structure in the PRC coating, and therefore the wear resistance is lower than that for the PC coating.

4. According to the corrosion test results obtained from 3 wt.\% $\mathrm{NaCl}$ solution, the highest corrosion resistance was obtained by DC, and the lowest corrosion resistance was obtained by $\mathrm{PRC}$. The following conclusion can be drawn from this:

Grain size is the essential factor in the resistance of corrosion of alloy coatings. The resistance of corrosion increased with an increase in grain size of $\mathrm{Ni}-\mathrm{B}$ alloy coatings.

\section{References}

[1] Sharma, Y. C.: Colloids Surf. A Physicochem. Eng. Asp., 215, 2003, p. 155. doi:10.1016/S0927-7757(02)00485-5

[2] Hena, S.: J. Hazard. Mater., 181, 2010, p. 474. doi:10.1016/j.jhazmat.2010.05.037

[3] Gardea-Torresdey, J. L.: J. Hazard. Mater., 80, 2000, p. 175. doi:10.1016/S0304 3894(00)00301-0.

[4] Riddle, Y. W., Bailer, T. O.: JOM, 57, 2005, p. 40. doi:10.1007/s11837-005-0080-7.

[5] Hou, K. H., Jeng, M. C., Ger, M. D.: Wear, 262, 2007, p. 833. doi:10.1016/j.wear.2006.08.023

[6] Tsai, W. T., Chung, S. T.: J. Supercrit. Fluids, 95, 2014, p. 292. doi:10.1016/j.supflu.2014.09.025

[7] Huang, P. C., Hou, K. H., Wang, G. L., Chen, M. L., Wang, J. R.: Int. J. Electrochem. Sci., 10, 2015, p. 4972 . 
[8] Houa, K. H., Wang, H. T., Sheuc, H. H., Gerca, M. D.: Appl. Surf. Sci., 308, 2014, p. 372. doi:10.1016/j.apsusc.2014.04.175.

[9] Torabinejad, V., Sabour Rouhaghdam, A., Aliofkhazraei, M., Allahyarzadeh, M. H.: J. Alloys Compd., 657, 2016, p. 526. doi:10.1016/j.jallcom.2015.10.154

[10] Srivastava, M., William Grips, V. K., Rajam, K. S.: Appl. Surf. Sci., 253, 2007, p. 3814. doi:10.1016/i.apsusc.2006.08.022

[11] Abdel Hamid, Z., Hassan, H. B., Attyia, A. M.: Surf. Coat. Technol., 205, 2010, p. 2348. doi:10.1016/j.surfcoat.2010.09.025

[12] Vitrya, V., Sensa, A., Kantab, A. F., Delaunoisa, F.: Appl. Surf. Sci., 263, 2012, p. 640. doi:10.1016/j.apsusc.2012.09.126

[13] Gaevskaya, T. V., Novotortseva, I. G., Tsybulskaya, L. S.: Met. Finish., 94, 1996, p. 100. doi:10.1016/0026-0576(96)83649-X

[14] Ogihara, H., Udagawa, K., Saji, T.: Surf. Coat. Technol., 206, 2012, p. 2933. doi:10.1016/i.surfcoat.2011.12.025

[15] Bekish, Y. N., Ponzyak, S. K., Tsybulskaya, L. S., Gaevskaya, T. V.: Electrochim. Acta, 55, 2010, p. 2223. doi:10.1016/j.electacta.2009.11.069

[16] Balaraju, J. N., Sankara Narayanan, T. S. N., Seshadri, S. K.: Mater. Res. Bull., 41, 2006, p. 847. doi:10.1016/j.materresbull.2005.09.024

[17] Lee, K. H.: Electrochim. Acta, 50, 2005, p. 4538. doi:10.1016/j.electacta.2004.03.067

[18] Krishnaveni, K., Sankara Narayanan, T. S. N., Seshadri, S. K.: Mater. Chem. Phys., 99, 2006, p. 300. doi:10.1016/j.matchemphys.2005.10.028
[19] López, J. R., Méndez, P. F., Pérez-Bueno, J. J., Trejo, G., Stremsdoerfer, G., Meas, Y.: Int. J. Electrochem. Sci., 11, 2016, p. 4231. doi:10.20964/2016.06.23

[20] Liang, Y., Li, Y. S., Yu, Q. Y., Zhang, Y. X., Zhao, W. J., Zeng, Z. X.: Surf. Coat. Technol., 264, 2015, p. 80. doi:10.1016/j.surfcoat.2015.01.016

[21] Ng, P. K., Snyder, D. D., LaSala, J., Clemens, B.: J. Electrochem. Soc., 135, 1988, p. 1376. doi:10.1149/1.2095994

[22] Peeters, P., Hoorn, G. V. D., Daenen, T., Kurowski, A.: Electrochim. Acta, 47, 2001, p. 161. doi:10.1016/S0013-4686(01)00546-1

[23] Houga, T., Yamada, A., Ueda, Y.: J. Jpn. Inst. Met., 64, 2000, p. 739. doi:10.2320/iinstmet1952.64.9_739

[24] Kainuma, S., Ishikura, S., Hisatake, K.: J. Magn. Soc. Jpn., 21, 1995, p. 889. doi:10.3379/imsimag.19.889

[25] Fransaer, J., Celis, J. P., Roos, J. R.: Met. Finish., 91, 1993, p. 97.

[26] Bredael, E., Blanpain, B., Celis, J. P., Roos, J. R.: J. Electrochem. Soc., 141, 1994, p. 294. doi:10.1149/1.2054703

[27] Daly, B. P., Barry, F. J.: Int. Mater. Rev., 48, 2003, p. 326. doi:10.1179/095066003225008482

[28] Chen, C. C., Liu, P., Lu, C. H.: Chem. Eng. J., 144, 2008, p. 509. doi:10.1016/j.cej.2008.07.047

[29] Karslioglu, R., Akbulut, H.: Appl. Surf. Sci., 353, 2015, p. 615. doi:10.1016/j.apsusc.2015.06.161

[30] Chang, C., Hsu, K., Ger, M., Wang, J.: Int. J. Electrochem. Sci., 12, 2017, p. 2055. doi:10.20964/2017.03.17

[31] Hansal, W. E. G., Sandulache, G., Mann, R., Leisner, P.: Electrochim. Acta, 114, 2013, p. 851. doi:10.1016/j.electacta.2013.08.182 